\title{
NADPH oxidase inhibitor VAS2870 prevents staurosporine-induced cell death in rat astrocytes
}

\author{
Janez Simenc, Damijana Mojca Juric, Metoda Lipnik-Stangelj \\ University of Ljubljana, Faculty of Medicine, Department of Pharmacology and Experimental Toxicology, Ljubljana, Slovenia \\ Radiol Oncol 2019; 53(1): 69-76. \\ Received 24 September 2018 \\ Accepted 18 November 2018 \\ Correspondence to: Prof. Metoda Lipnik-Stangelj, M.D., M.Pharm., Ph.D., University of Ljubljana, Faculty of Medicine, \\ Department of Pharmacology and Experimental Toxicology, Korytkova ulica 2, SI-1000 Ljubljana, Slovenia. Phone: +386 15437330 ; \\ E-mail: metoda.lipnik-stangelj@mf.uni-lj.si \\ Disclosure: No potential conflicts of interest were disclosed.
}

Background. Astrocytes maintain central nerve system homeostasis and are relatively resistant to cell death. Dysfunction of cell death mechanisms may underlie glioblastoma genesis and resistance to cancer therapy; therefore more detailed understanding of astrocytic death modalities is needed in order to design effective therapy. The purpose of this study was to determine the effect of VAS2870, a pan-NADPH oxidase inhibitor, on staurosporine-induced cell death in astrocytes.

Materials and methods. Cultured rat astrocytes were treated with staurosporine as activator of cell death. Cell viability, production of reactive oxygen species (ROS), and mitochondrial potential were examined using flow cytometric analysis, while chemiluminescence analysis was performed to assess caspase 3/7 activity and cellular ATP.

Results. We show here for the first time, that VAS2870 is able to prevent staurosporine-induced cell death. Staurosporine exerts its toxic effect through increased generation of ROS, while VAS2870 reduces the level of ROS. Further, VAS2870 partially restores mitochondrial inner membrane potential and level of ATP in staurosporine treated cells.

Conclusions. Staurosporine induces cell death in cultured rat astrocytes through oxidative stress. Generation of ROS, mitochondrial membrane potential and energy level are sensitive to VAS2870, which suggests NADPH oxidases as an important effector of cell death. Consequently, NADPH oxidases activation pathway could be an important target to modulate astrocytic death.

Key words: astrocytes; VAS2870; mitochondrial potential; ATP; reactive oxygen species; cell death

\section{Introduction}

Astrocytes are the most abundant non-excitatory cell type in the central nervous system (CNS), where they play a key role in brain development and survival of neurons. ${ }^{1}$ They maintain CNS homeostasis, modulate neuronal excitation, synaptic transmission and brain plasticity..$^{2-5}$ Generally, astrocytes are more robust than neurons and are highly resistant to apoptosis. ${ }^{6}$ However, traumatic brain injury, infection, or various neurodegenerative diseases, with subsequent ischemia-hypoxia, calcium overload or oxidative stress, can induce extensive astrocytic demise. ${ }^{7-9}$ On the other hand, it is believed that the dysfunction of cell death in astrocytes underlies glioblastoma genesis, proliferation, and resistance to therapy. ${ }^{10-13}$ Therefore, it is of immense importance to better understand cell death mechanisms in astroglial cells, either for the design of more effective therapies to prevent cell death in case of trauma and neurodegenerative disease, or to improve anti-cancer agents and limit the likelihood of resistance development in glioblastoma. 
Diverse stimuli may induce cell death with distinctive molecular and cellular characteristics. In this sense, apoptosis is a form of regulated cell removal, mainly mediated by cysteine proteasescaspases and characterized by gradual cell degradation with intact plasma membrane till the late phase of the process. ${ }^{14}$ On the contrary, necrosis is a cell death form which is independent of caspases and is characterized by rapid cell collapse due to early loss of plasma membrane integrity and dissipation of the mitochondrial transmembrane potential. ${ }^{15}$ The membrane pores can release cytoplasmic components outside the cell, where they can evoke inflammatory response and additional cell lose. ${ }^{8,16}$ Necrosis may happen accidental due to overwhelming stress, but may occur as another regulated form of cell death - necroptosis, mediated through receptor-interacting serine-threonine (RIP1 and RIP3) kinases activity. ${ }^{17}$

Degradation of electron transport chain may increase the production of reactive oxygen species (ROS) and hence contribute to apoptosis. ${ }^{18}$ On the other hand the execution of necroptosis downstream of RIP kinases activity also depends on ROS overproduction. In addition to damaged mitochondria, another important source of ROS could be the nicotinamide adenine dinucleotide phosphate (NADPH) oxidases activity. ${ }^{19,20}$ In the CNS, expression of several NADPH oxidase isoforms has been described in neurons, microglia and astrocytes, with different functions, both in health and disease..$^{21,22}$

Previously we reported that staurosporine, a broad-spectrum protein kinase inhibitor, is able to trigger cell death in cultured rat cortical astrocytes through caspases dependent pathways as well as through RIP1 kinase activity. ${ }^{23,24}$ Here we explored whether VAS2870, a pan-NADPH oxidase inhibitor, is able to inhibits staurosporine induced cell death in cultured rat astrocytes. Also, we checked how VAS2870 mechanically operates in preventing cell death, since we determined the effect of VAS2870 on staurosporine-induced ROS production, mitochondrial function and ATP level in cultured rat cortical astrocytes.

\section{Materials and methods}

\section{Materials}

Bovine serum albumin (BSA), Fetal bovine serum (FBS), L-15 Leibowitz medium, Dulbecco's modified Eagle medium and Ham's nutrient mixture F-12 (DMEM/F12), Penicillin (10,000 IU/ $\mathrm{ml})$, Streptomycin $(10,000 \mathrm{mg} / \mathrm{ml})$, Dulbecco's phosphate buffered saline (PBS) were supplied from Gibco BRL, Life Technologies (Paisley, Scotland). Staurosporine, 3-benzyl-7-(2-benzoxazolyl) thio-1,2,3-triazolo[4,5-d]pyrimidine (VAS2870), 3,3'-dihexyloxacarbo-cyanide iodide (DiOC6(3)), and 2-7-dichlorodihydrofluorescin diacetate (DCFH-DA) were purchased from Sigma Chemicals (St. Louis, Missouri, USA). The pancaspase inhibitor (z-vad-fmk) was purchased from R\&D Systems (Minneapolis, Minnesota, USA). 7-Aminoactinomycin D (7-AAD) staining dye for flow cytometry was purchased from BeckmanCoulter, Inc. (Brea, California, USA). Bio-Rad protein assay kit was purchased from Bio-Rad Laboratories, München, Germany. 1,2-diaminocyclohexanetetraacetic acid (DCTA), dithiothreitol (DTT), Triton X-100, Tris-phosphate, and glycerol were supplied from Merck KGaA, Darmstadt, Germany. ATPlite 1-step assay system was supplied from Perkin Elmer, Boston, Massachusetts, USA. Caspase-Glo 3/7 Assay was purchased from Promega, Madison, Wisconsin, USA.

\section{Animals}

New-born Wistar rats (1-2 days old) were obtained from our own breeding colony. The animals were kept under constant environmental conditions with an ambient temperature of $22^{\circ} \mathrm{C}$, relative humidity $55 \%$, and a natural light-dark cycle. The breeding colony was kept in Ehret type-4 cages (Emmerdingen, Germany). The bedding material was Lignocel 3/4 (Altromin, Lage, Germany). The colony received a standard rodent diet (Altromin, Germany), and had free access to food and water. All animal studies were approved by the Veterinary Authority of the Republic of Slovenia (License number: 34401-7/2012/3), and performed in accordance with the EU Directive 2010/63/EU and the European Convention for the protection of vertebrate animals used for experimental and other scientific purposes (ETS 123).

\section{Cell cultures}

Cultures of rat cortical astrocytes were prepared from the brain of new-born rats in DMEM/F12 (1:1), $10 \%$ FBS, $1 \%$ Penicillin-Streptomycin culture medium as described previously. ${ }^{24}$ The cells were grown in tissue culture flasks at $37^{\circ} \mathrm{C}$ in a humidified environment containing $10 \% \mathrm{CO}_{2}$ until they became confluent (10 to 12 days). In order to reduce microglia contamination, confluent cultures 
were shaken at $150 \mathrm{rpm}$ for a day. After shaking, the cells were trypsinized, reseeded onto $35 \mathrm{~mm}$ Petri dishes (approx. $1 \times 10^{6}$ cells $/ \mathrm{ml}$ ) and grown for the next 5 to 7 days. When the cultures reached confluence, they were used for the treatment. The purity of the cell culture (>98\% of astrocytes) was checked using immuno-cytochemical staining for the glial fibrillary acidic protein, which is the major component of the astrocyte cytoskeleton.

\section{Induction and inhibition of cell death}

After the cultures became confluent, culture medium was replaced with $1 \mathrm{ml}$ of fresh serum-free medium. Then the cells were treated with $1 \mu \mathrm{M}$ staurosporine for 3 hours, to induce cell death. After the treatment, the cells were allowed to regenerate for 22 hours in a staurosporine-free medium. The control cells were not exposed to staurosporine.

For the inhibition experiments, the cells were pre-treated with 5 and $10 \mu \mathrm{M}$ VAS2870 or $20 \mu \mathrm{M}$ $\mathrm{z}$-vad-fmk, 1 hour before $1 \mu \mathrm{M}$ staurosporine was added. Then the cells were incubated for an additional 3 hours. The cells were then regenerated in the staurosporine, VAS2870 and z-vad-fmk free medium for 22 hours. The cells were also exposed to 5 and $10 \mu \mathrm{M}$ VAS2870 or to $20 \mu \mathrm{M}$ z-vad-fmk only for 3 hours and allowed to regenerate in an inhibitor-free medium for 22 hours.

For the testing of viability, ROS and mitochondrial potential, the cells were trypsinized and stained for an analysis in a flow cytometer. For the detection of caspases-3/7 activity and level of cellular ATP, the cells were harvested and solubilized in a cell culture lysis buffer.

\section{Viability determination}

The cells from individual dishes $\left(1-5 \times 10^{6} \mathrm{cells} / \mathrm{ml}\right)$ were stained with 7-AAD viability dye, according to the manufacturer's protocol. Briefly, the cells were harvested and washed in the ice cold PBS (500 $\mu \mathrm{l})$. Then the cells were re-suspended in $100 \mathrm{ml}$ PBS buffer with $1 \%$ BSA and $0.1 \% \mathrm{NaN}_{3}$. The cell suspension was stained with $20 \mathrm{ml}$ of 7-AAD solution and incubated at $4^{\circ} \mathrm{C}$ for 15 minutes. After the incubation, an additional $400 \mu \mathrm{l}$ PBS buffer with $1 \%$ BSA and $0.1 \% \mathrm{NaN}_{3}$ was added. Aliquots $(200 \mu \mathrm{l})$ of cell suspensions were analysed on the Quanta SC MPL flow cytometer (Beckman Coulter, USA) with $488 \mathrm{~nm}$ argon laser. In each sample, approximately 5.000 cells were gated. Gating was done in a hierarchical fashion. First, total cell population was identified by plotting electronic volume (EV) ver- sus side scatter (SSC). High EV and SSC population was gated. Next, viability (red fluorescence) scatter gate was used to identify dead cells. Three populations were observed: viable, dim and positive. The positive population (high red signal) was considered dead. The dead population was identified and gated by comparison of treated cells to untreated (negative) controls.

\section{Detection of caspases-3/7 activity and cellular ATP}

Harvested cells from individual dishes were solubilized in a $150 \mu \mathrm{l}$ of cell culture lysis buffer (250 mM Tris-phosphate $\mathrm{pH} 7.8,2 \mathrm{mM}$ DCTA, $2 \mathrm{mM}$ DTT, $1 \%$ Triton X-100, 10\% glycerol). Aliquots (5 $\mu \mathrm{l})$ of cell samples were used for determination of protein concentrations by Bio-Rad protein assay kit. Cellular ATP concentration was determined with the ATPlite 1-step assay system as described in the manufacturer's manual. The chemiluminescent signals were measured by a Synergy HT microplate reader (BioTek USA). The amount of ATP in each sample, diluted to contain $1 \mathrm{mg}$ protein $/ \mathrm{mL}$, was calculated using a generated standard ATP curve (1 pM - $1 \mathrm{mM})$. The same samples were used for detection of caspases-3/7 activity by Caspase-Glo 3/ 7 Assay (Promega, Madison, USA) as described in the manufacturer's manual.

\section{Detection of ROS and mitochondrial potential}

After the treatment, the cells $\left(1-5 \times 10^{6}\right.$ cells $\left./ \mathrm{ml}\right)$ were harvested and washed in the PBS $(500 \mu \mathrm{l})$. For the detection of ROS production, the cells were resuspended in $500 \mathrm{ml}$ of PBS at room temperature and stained with $2 \mu \mathrm{M}$ DCFH-DA, as proposed by manufacturer's protocol. Similar, for the detection of inner mitochondrial membrane potential, the cells were stained with $100 \mathrm{nM}$ DiOC6(3), as described in the manufacturer's manual. After the staining for either the detection of ROS or mitochondrial potential, the cell suspensions were incubated at $37^{\circ} \mathrm{C}$ for 30 minutes. Aliquots $(200 \mu \mathrm{l})$ of cell suspensions were analysed on the Quanta SC MPL flow cytometer (Beckman Coulter, USA) with $488 \mathrm{~nm}$ argon laser. Gating was done in a hierarchical fashion. First, total cell population (approximately 5.000 cells) was identified by plotting EV versus SSC. High EV and SSC population was gated. Then ROS (green fluorescence) scatter plot was used to identify the level of ROS and untreated (negative) controls were used to set the gate for 
high ROS population. Similar strategy was used for the identification of low mitochondrial membrane potential cell population. First, high EV and SSC population was identified. Next, green fluorescent histogram was plotted with marker showing low potential population. As previously, untreated (negative) cells were used to identify low mitochondrial membrane cell population.

\section{Statistical analyses}

All data are presented as a mean \pm SEM of three to five determinations from five independent experiments. Data analysis was performed using Graph Pad Prism 5.0 (Graph Pad Software, Inc., USA). The statistical significance of differences between various groups was evaluated using one-way ANOVA followed by the Tukey multiple comparison test. A $p$ value of $<0.05$ was considered to be statistically significant.
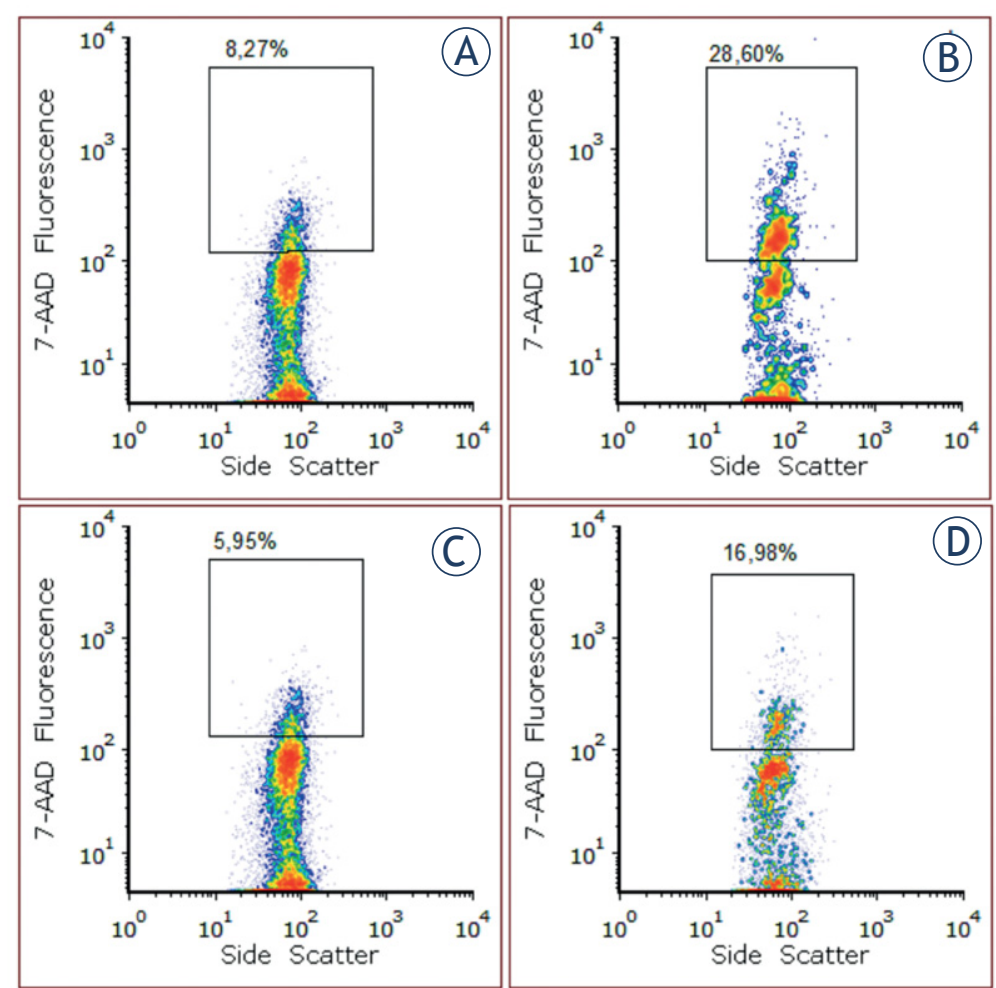

\section{Results}

\section{VAS2870 inhibits staurosporine-induced cell death in astrocytes}

$3 \mathrm{~h}$ treatment with $1 \mu \mathrm{M}$ staurosporine revealed a significant cytotoxic effect on cultured astrocytes causing $27.1+/-0.8 \%$ decrease of viability as detected by high red fluorescent signal in a flow cytometry (Figure 1). Pre-treatment with $5 \mu \mathrm{M}$ VAS2870 reduced cell death by 1.3 -fold, whereas $10 \mu \mathrm{M}$ VAS2870 diminished staurosporine-triggered cell death even more, by 1.7 -fold. In untreated control cells, on average $7.8+/-0.6 \%$ of dead cells was detected. The proportions of dead cells in the culture exposed to VAS2870 alone were low and did not differ significantly from the untreated controls (Figure 1).

\section{Staurosporine induces caspases-3/7 activity and reduces level of ATP in rat astrocytes}

$1 \mu \mathrm{M}$ staurosporine activated caspases-3/7 (Figure 2A), a key indicator of the execution phase of apoptotic cell death. While pre-incubation of cultured astrocytes with $20 \mu \mathrm{M} z$-vad-fmk lowered the activity of caspases-3/7 by 13.9-fold in comparison to the cells, treated by staurosporine alone, pre-treatment of the cells with $10 \mu \mathrm{M}$ VAS2870 did not significantly inhibit caspases-3/7 activity. In the untreated controls, VAS2870 or z-vad-fmk caused no caspases-3/7 activation.

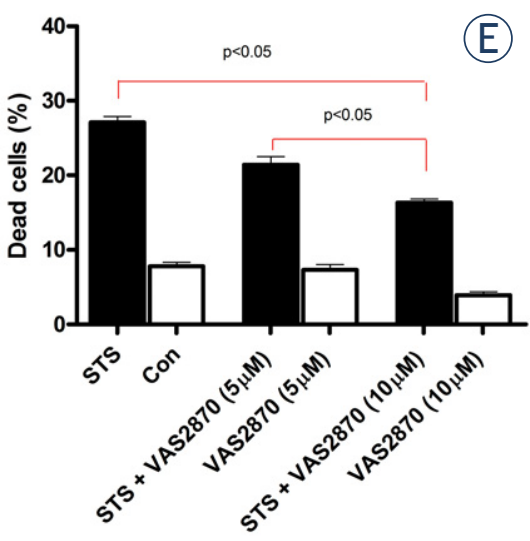

FIGURE 1. The effect of staurosporine on viability of rat astrocytes. Representative flow cytometric experiment is showing the uptake of 7-AAD vital dye in rat astrocytes. The percentages of dead cells with high red fluorescence intensity are shown in rectangular regions. (A) The control cells were not treated. (B) The cells were exposed to $1 \mu \mathrm{M}$ staurosporine. (C) The cells were exposed to $10 \mu \mathrm{M}$ VAS2870. (D) The cells were pre-treated with $10 \mu \mathrm{M}$ VAS2870 and exposed to $1 \mu \mathrm{M}$ staurosporine. (E) The percentages of dead cells as determined by 7-AAD uptake. (Con) The control cells were not treated. (STS) The cells were exposed to $1 \mu \mathrm{M}$ staurosporine. (STS+VAS2870) The cells were pre-treated with 5 or $10 \mu \mathrm{M}$ VAS2870 and exposed to $1 \mu \mathrm{M}$ staurosporine. (VAS2870) The cells were exposed to 5 or $10 \mu \mathrm{M}$ VAS2870. Data were analysed using one-way ANOVA and a Tukey multiple comparison test; $p<0.05$ indicates significance. 
Furthermore, staurosporine critically reduced cellular energetic supply in astrocytes, decreasing the level of intracellular ATP by 15.9-fold compared to untreated controls, which represents $0.59+/-0.08$ $\mathrm{nM}$ ATP/mg cell protein. While in the cells, pretreated with z-vad-fmk, the level of ATP remained low and did not differ significantly from the staurosporine treated cells (Figure 2B), pre-treatment of the cells with VAS2870 partially reversed the level of ATP, which represents 6.51-fold enhancement in comparison to the cells, treated by staurosporine. In the cells, exposed to either VAS2870 or z-vadfmk only, the level of ATP remained high and did not differ significantly from the untreated cells $(9.30+/-0.56 \mathrm{nM}$ ATP/mg cell protein) (Figure 2B).

\section{VAS2870 reduces level of ROS in rat astrocytes}

VAS2870 (5 and $10 \mu \mathrm{M}$ ) was applied to staurosporine-treated cells as a putative inhibitor of ROS production. Detection of ROS was performed with DCFH-DA probe by flow cytometry. In each exper-
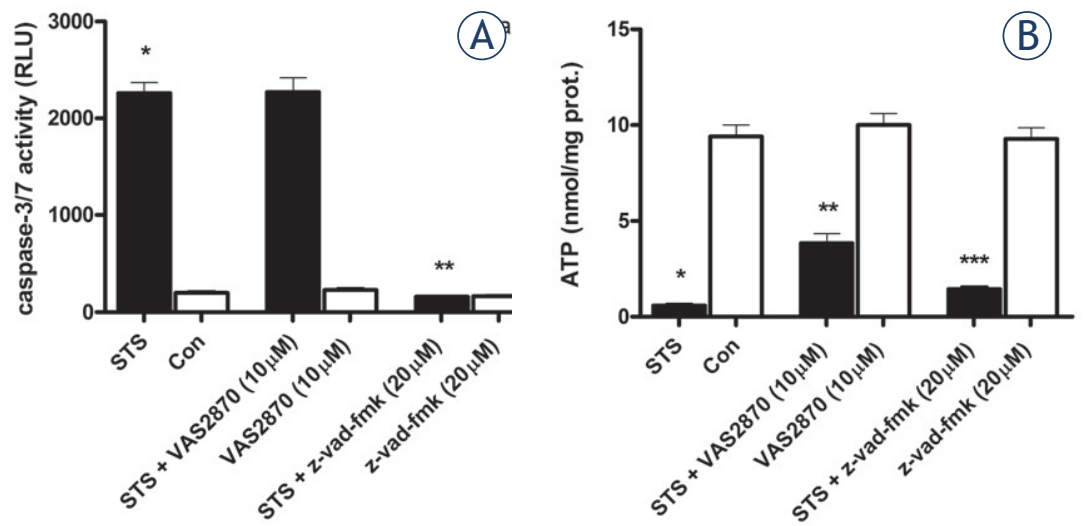

FIGURE 2. (A) The effect of staurosporine on caspases-3/7 activation and (B) level of intracellular ATP. (STS) The cells were exposed to $1 \mu \mathrm{M}$ staurosporine. (Con) The control cells were not treated. (STS+VAS2870) The cells were pre-treated with $10 \mu \mathrm{M}$ VAS2870 and exposed to $1 \mu \mathrm{M}$ staurosporine. (VAS2870) The cells were exposed to $10 \mu \mathrm{M}$ VAS2870. (STS + z-vad-fmk) The cells were pre-treated with $20 \mu \mathrm{M} z$-vadfmk and exposed to $1 \mu \mathrm{M}$ staurosporine. (z-vad-fmk) The cells were exposed to 20 $\mu M$ z-vad-fmk. Data were analysed using one-way ANOVA and a Tukey multiple comparison test; ${ }^{*} p<0.05$ vs. Con, ${ }^{* *} p<0.05$ vs. STS, ${ }^{* * *} p<0.05$ vs STS + VAS 2870 indicate significance. RLU- relative luminescence units.
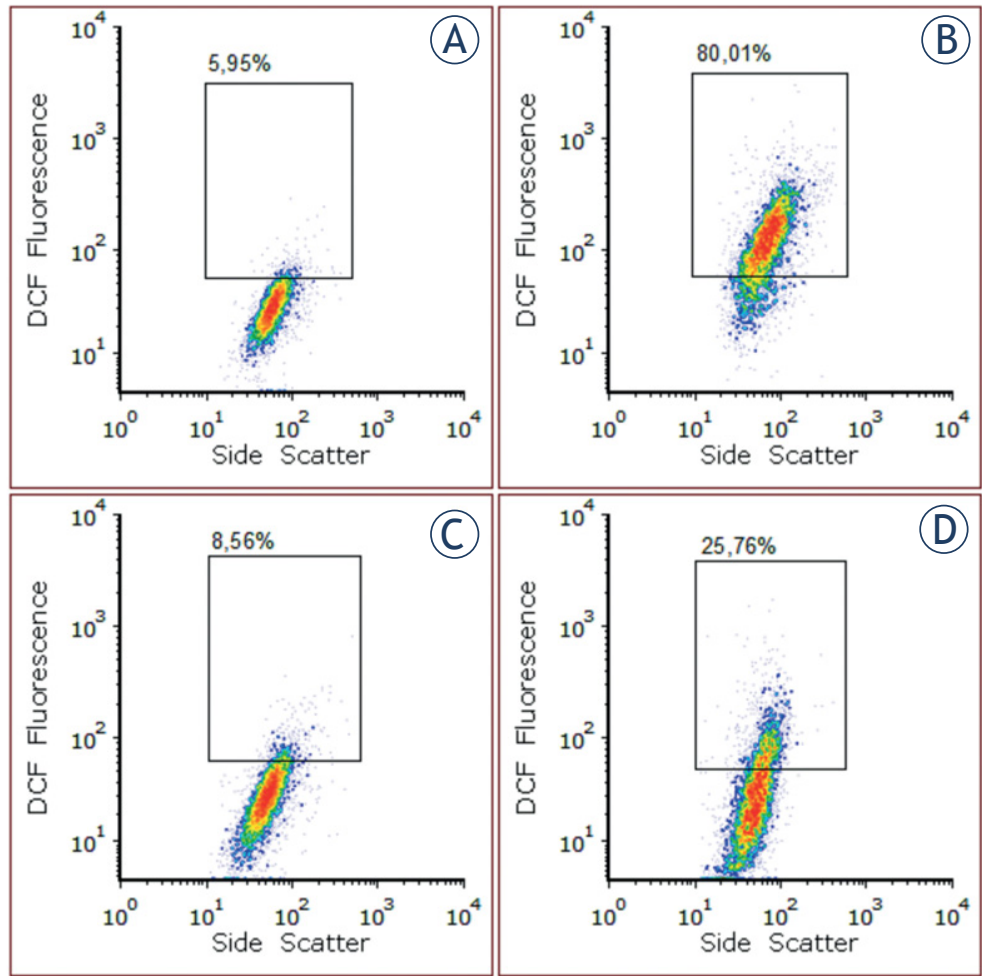

iment, fluorescence intensity of dichlorofluorescin (DCF), a product of DCFH-DA degradation and oxidation, was detected (Figure 3A-D). The results showed that $1 \mu \mathrm{M}$ staurosporine induces ROS production; on average $81.6+/-1.8 \%$ of DCF fluorescent cells was detected (Figure 3E) and ROS production was increased by 10.2-fold. Pre-treatment with $5 \mu \mathrm{M}$ VAS2870 reduced the levels of ROS by 1.6-fold, while $10 \mu \mathrm{M}$ VAS2870 diminished ROS

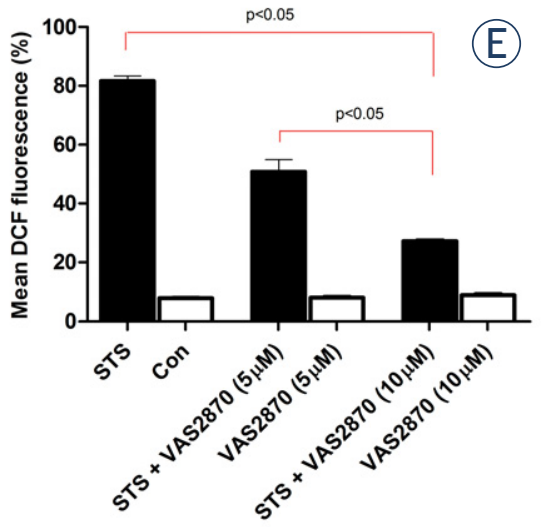

FIGURE 3. Representative flow cytometric experiment is showing detection of ROS production in rat astrocytes after staurosporine activation. The percentages of cells with high DCF fluorescence intensity are shown in rectangular regions. (A) Untreated control cells. (B) The cells were exposed to 1 $\mu \mathrm{M}$ staurosporine. (C) The cells were exposed to $10 \mu \mathrm{M}$ VAS2870. (d) The cells were pre-treated with $10 \mu \mathrm{M}$ VAS2870 and exposed to $1 \mu \mathrm{M}$ staurosporine. (E) Production of ROS, detected as the percentage of cells with high DCF fluorescence intensity. (STS) The cells were exposed to $1 \mu M$ staurosporine. (Con) Untreated control cells. (STS + VAS2870) The cells were pre-treated with 5 or $10 \mu M$ VAS2870 and exposed to $1 \mu M$ staurosporine. (VAS2870) The cells were exposed to 5 or $10 \mu \mathrm{M}$ VAS2870. Data were analysed using one-way ANOVA and a Tukey multiple comparison test; $p<0.05$ indicates significance. 
levels 3.0-fold compared to the cells, treated by staurosporine (Figure 3E). VAS2870 itself showed no influence on ROS production (Figure 3E).

\section{VAS2870 restores mitochondrial potential in rat astrocytes}

The potential of inner mitochondrial membrane $\left(\mathrm{Dpsi}_{\mathrm{m}}\right)$ was measured with DiOC6(3) potentiometric dye using flow cytometry. DiOC6(3) is taken up into the healthy cell and distributed across the inner mitochondrial membrane. The collapse of proton gradient across inner mitochondrial membrane of dying cells results in the loss of DiOC6(3) and hence loss of fluorescence intensity. In each experiment, green fluorescent signal of $\mathrm{DiOC6}(3)$ was analysed, identifying regions with low fluorescence intensity. As depicted in the representative flow cytometric experiment (Figure 4), $1 \mu \mathrm{M}$ staurosporine potently reduced mitochondrial potential. The proportion of the cells with low mitochondrial potential was increased by 7.3 -fold as compared to untreated controls (Figure 4B, E), while the untreated control cells and VAS2870 treated cells yielded a high fluorescent signal (Figure 4A, C). When astrocytes were pre-incubated with 5 $\mu \mathrm{M}$ VAS2870, the potential was partially restored (Figure 4E), whereas $10 \mu \mathrm{M}$ VAS2870 restored the potential even more, as evidenced by 2.6 -fold decrease of low potential cells compared to staurosporine only treated cells (Figure 4D, E).

\section{Discussion}

Astroglial cells death could be executed through different pathways, where increased production of ROS plays a critical role. In the present work, we triggered cell death in rat cortical astrocytes by staurosporine which is known to induce caspasesdependent and -independent cell death in many cell types, ${ }^{25,26}$ including astrocytes. ${ }^{24,27}$ Indeed, staurosporine significantly increased proportion of death cells, as indicated by the bright population of 7-AAD positive cells (Figure 1).

Staurosporine increased caspases-3/7 activity, which indicates apoptosis (Figure 2A). Further, the production of ATP in astrocytes was significantly reduced, which surprisingly could not be preserved by pan-caspase inhibitor (Figure 2B). This observation suggests that necroptosis also occurred, which is in accordance with the findings of Leist et al. ${ }^{28}$, where depletion of intracellular ATP has been associated with a switch from apoptosis to necroptosis. It seems that in our experimental model, both forms of cell death coexist. This is in line with our previous report, where we showed that staurosporineinduced cell death in rat cortical astrocytes could be partially inhibited by necrostatin-1, an inhibitor of RIP1 kinase activity. ${ }^{24}$ Similar observation was described in neurons, where staurosporine at higher concentrations induced necroptosis and not apoptosis. ${ }^{29}$ Importantly, as shown in Figure 1, VAS2870 reduced cell death, triggered by staurosporine
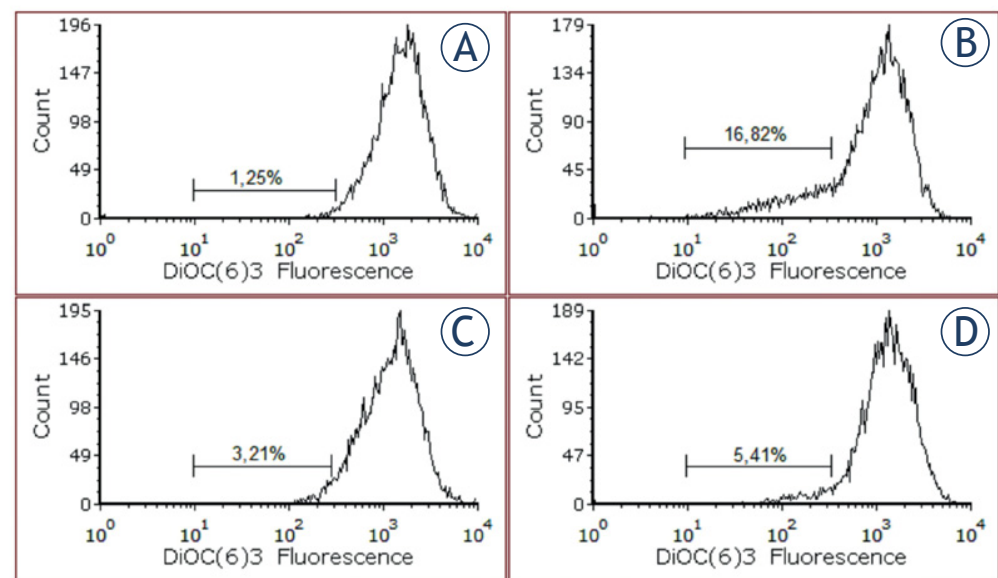

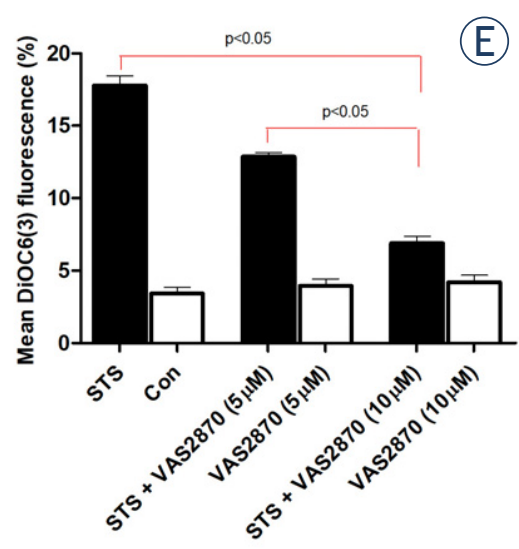

FIGURE 4. A representative flow cytometric experiment is showing the DiOC6(3) fluorescence intensity in rat astrocytes. The markers show the percentage of cells with reduced mitochondrial potential. (A) Untreated control cells. (B) The cells were exposed to $1 \mu M$ staurosporine. (C) The cells were exposed to $10 \mu \mathrm{M}$ VAS2870. (D) The cells were pre-treated with $10 \mu \mathrm{M}$ VAS2870 and exposed to $1 \mu \mathrm{M}$ staurosporine. (E) The reduction of mitochondrial potential, detected as the percentage of low DiOC6(3) fluorescence. (STS) The cells were exposed to $1 \mu$ M staurosporine. (Con) Untreated control cells. (STS+VAS2870) The cells were pre-treated with 5 or $10 \mu \mathrm{M}$ VAS2870 and exposed to $1 \mu \mathrm{M}$ staurosporine. (VAS2870) The cells were exposed to 5 or $10 \mu \mathrm{M}$ VAS2870. Data were analysed using one-way ANOVA and a Tukey multiple comparison test; $\mathrm{p}<0.05$ indicates significance. 
and, contrary to z-vad-fmk, VAS2870 also significantly preserved the level of ATP (Figure 2B). Since VAS2870 has been shown as a specific pan-NADPH oxidase inhibitor ${ }^{30}$, our observations indicate that necroptosis could be mediated through NADPH oxidases activity. However other anti-necrotic or pro-survival effects of VAS2870 could not be excluded and require further investigation.

The programmed cell death, in particular necroptosis, is executed through increased generation of ROS in several cell types, ${ }^{19,31}$ including rat astrocytes. ${ }^{23}$ Since VAS2870 operates as a powerful inhibitor of ROS generation, we explored the influence of VAS2870 on ROS production. Indeed, as shown in Figure 3E, VAS2870 significantly reduced ROS production at concentrations where probably does not act as an antioxidant. ${ }^{30}$ However, in the untreated control cells, some basic level of ROS still remained which may be due to ROS generation at the mitochondrial respiratory chain, as has been shown by Vanlangenakker et $a l .32$ Functionally, staurosporine generates oxidative stress as underlying mechanisms of cell death in cultured rat astrocytes and this mechanism is sensitive to VAS2870. Similar to our observations, staurosporine-induced cell demise and ROS generation in cultured rat astrocytes was efficiently reduced by broad serine protease inhibitor - AEBSF. ${ }^{33}$ Our results are also in agreement with the model of necroptosis, triggered by hemin in mouse astrocytes, where hemin induced necroptosis through increased ROS and rapid depletion of intracellular reduced glutathione, while necroptosis, ROS and glutathione depletion were significantly reduced by apocynin, another pharmacological inhibitor of NADPH oxidases..$^{34}$ Overall, these observations indicate that NADPH oxidases are an effector of cell death in astrocytes. If this is the case, it remains to be established, how the NADPH oxidases are activated to mediate cell death. One possibility is that they are activated in the necrosome, as has been shown in L929 and MEF cells during tumour necrosis factor induced necroptosis. ${ }^{31}$ Alternatively, the NADPH oxidases may mediate cell death independently of necrosome; however, both signalling pathways are needed. Interestingly, Liu et al. ${ }^{35}$ reported that activation of NADPH oxidases and increased ROS are necessary for astrocytes to survive when challenged with calcium ionophore or opsonized zymosan. Taken together, these findings suggest a pivotal role of NADPH oxidases both in astrocyte survival and death under chemical stress or pathological conditions.
In astrocytes, mitochondrial function is fundamental for maintaining the energetic balance of the brain and antioxidant production that contributes to neuronal protection. ${ }^{36}$ Due to high amounts of redox enzymes with sulphur iron centres in the mitochondria, we reasoned that ROS could have an adverse effect on the mitochondrial potential and thus we analysed the potential of inner mitochondrial membrane. As shown in Figure 4, staurosporine indeed reduced the inner mitochondrial membrane potential, while the potential was almost restored when the cells were pre-treated with VAS2870. This observation is corroborated with partially restored level of ATP in VAS2870 pre-treated cells. Mitochondrial depolarization is a part of cell death execution and it can be limited by VAS2870, hence it may operate downstream of NADPH oxidases activity. At least part of ROS is exogenous, probably derived either from cellmembrane or mitochondrial NADPH oxidases. ${ }^{37}$ Therefore mitochondria are also the target and not only the source of ROS. In contrast to our observation, Remijsen et al. ${ }^{38}$ demonstrated in L929 cells that mitochondrial depolarization does not occur during tumour necrosis factor induced cell death. The mitochondrial depolarization during necroptosis seems to depend on the cell type or the exact stimulus to initiate cell death.

\section{Conclusions}

Our results show that staurosporine-induced cell death in rat astrocytes involves generation of ROS, and is sensitive to VAS2870. Also, mitochondrial depolarization and depletion of ATP are part of cell death process and may be partially reversed by VAS2870. We conclude that NADPH oxidases activation pathway may be useful target to execute cell death. In addition, our observations add to the recognition of astrocytes as an important source of ROS, which may significantly contribute to various pathologies, such as traumatic brain injury, haemorrhagic stroke, neurodegenerative disorders and cancer.

\section{Acknowledgement}

The authors acknowledge the financial support from the Slovenian Research Agency (research core funding No. P3-0067). The authors wish to thank Mojca Kranjec for her excellent technical assistance. 


\section{References}

1. Wozniak W. Ependymal cells and astrocytes generate neurones. Folia Morphol (Warsz) 1999; 58(3 Suppl 2): 7-11. PMID: 10959256

2. Magistretti PJ, Pellerin L. Astrocytes couple synaptic activity to glucose utilization in the brain. News Physiol Sci 1999; 14: 177-82. PMID: 11390847

3. Perea G, Araque A. Astrocytes potentiate transmitter release at single hippocampal synapses. Science 2007; 317: 1083-86. doi: 10.1126/science. 1144640

4. Stogsdill JA, Ramirez J, Liu D, Kim, YH, Baldwin KT, Enustun E, et al. Astrocytic neuroligins control astrocyte morphogenesis and synaptogenesis. Nature 2017; 551: 192-97. doi: 10.1038/nature24638

5. Papouin T, Dunphy J, Tolman M, Foley JC, Haydon PG. Astrocytic control of synaptic function. Philos Trans R Soc Lond B Biol Sci 2017; 5: 372(1715 pii:20160154. doi: 10.1098/rstb.2016.0154

6. Song JH, Bellail A, Tse CLM, Yong Wee V, Hao C. Human astrocytes are resistant to Fas ligand and Tumor necrosis factor related apoptosis inducing ligand induced apoptosis. J Neurosci 2006; 26: 3299-308. doi: 10.1523/JNEUROSCI.5572-05.2006

7. Jurič DM, Finderle Ž, Šuput D, Brvar M. The effectiveness of oxygen therapy in carbon monoxide poisoning is pressure- and timedependent: a study on cultured astrocytes. Toxicol Lett 2015; 233: 16-23. doi: 10.1016/j.toxlet.2015.01.004

8. Leyns CEG, Holtzman D. Glial contributions to neurodegeneration in tauopathies. Mol Neurodegener 2017; 12: 50. doi: 10.1186/s13024-0170192-x

9. Dos Santos AA, López-Granero C, Farina M, Rocha JBT, Bowman AB, Aschner M. Oxidative stress, caspase-3 activation and cleavage of ROCK-1 play an essential role in MeHg-induced cell death in primary astroglial cells. Food Chem Toxicol 2018; 113: 328-36. doi: 10.1016/j.fct.2018.01.057

10. Jiang YG, Peng $Y$, Koussougbo KS. Necroptosis: a novel therapeutic target for glioblastoma. Med Hypotheses 2011; 76: 350-52. doi: 10.1016/j.mehy.2010.10.037

11. Fulda S. Cell death-based treatment of glioblastoma. Cell Death Dis 2018; 9 121. doi: 10.1038/s41419-017-0021-8

12. Smrdel U, Skoblar-Vidmar M, Smrdel A. Glioblastoma in patients over 70 years of age. Radiol Oncol 2018; 52: 167-72. doi: 10.2478/raon-2018-0010

13. Kazda T, Dziacky A, Burkon P, Pospisil P, Slavik M, Rehak Z, et al. Daily clinical radiotherapy of glioblastoma 15 years after the landmark Stupp' trial: more controversies than standards? Radiol Oncol 2018; 52: 121-8. doi: 10.2478/ raon-2018-0023

14. Taylor RC, Cullen SP, Martin SJ. Apoptosis: controlled demolition at the cellular level. Nature Rev 2008; 9: 231-41. doi: 10.1038/nrm2312

15. Degterev A, Huang Z, Boyce M, Li Y, Jagtap P, Mizushima N, et al. Chemical inhibitor of nonapoptotic cell death with therapeutic potential for ishemic brain injury. Nat Chem Biol 2005; 2: 112-9. doi: 10.1038/nchembio711

16. Scaffidi $\mathrm{P}$, Misteli $T$, Bianchi ME. Release of chromatin protein HMGB1 by necrotic cells triggers inflammation. Nature 2002; 418: 191-5. doi: $10.1038 /$ nature00858

17. Oberst $A$, Dillon $C P$, Weinlich $R$, McCormick $L L$, Fitzgerald $P$, Pop $C$, et al. Catalytic activity of the caspase-8-FLIP(L) complex inhibits RIPK3 dependent necrosis. Nature 2011; 471: 363-7. doi: 10.1038/nrm3214

18. Ricci JE, Muñoz-Pinedo C, Fitzgerald P, Bailly-Maitre B, Perkins GA, Yadava N, et al. Disruption of mitochondrial function during apoptosis is mediated by caspase clevage of the p75 subunit of complex I of the electron transport chain. Cell 2004; 117: 773-86. doi: 10.1016/j.cell.2004.05.008

19. Zhang DW, Shao J, Lin J, Zhang N, Lu BJ, Lin SC, et al. RIP3, an energy metabolism regulator that switches TNF-induced cell death from apoptosis to necrosis. Science 2009; 325: 332-6. doi: 10.1126/science.1172308

20. Dong W, Li Z, Chen Y, Zhang L, Ye Z, Liang H, et al. NADPH oxidase inhibitor diphenyleneiodonium prevents necroptosis in HK-2 cells. Biomed Rep 2017; 7: 226-30. doi: 10.3892/br.2017.948

21. Nayernia Z, Jaquet $\mathrm{V}$, Krause $\mathrm{KH}$. New insights on NOX enzymes in the central nervous system. Antioxid Redox Signal 2014; 20: 2815-37. doi: 10.1089/ars.2013.5703
22. Haslund-Vinding J, McBean G, Jaquet V, Vilhardt F. NADPH oxidases in oxidant production by microglia: activating receptors, pharmacology and association with disease. Br J Pharmacol 2017; 174: 1733-49. doi: $10.1111 /$ bph.13425

23. Simenc J, Lipnik-Stangelj M. Staurosporine induces different cell death forms in cultured rat astrocytes. Radiol Oncol 2012; 46: 312-20. doi: 10.2478/ v10019-012-0036-9

24. Šimenc J, Lipnik-Štangelj M. Staurosporine induces apoptosis and necroptosis in cultured rat astrocytes. Drug Chem Toxicol 2012; 35: 399405. doi: 10.3109/01480545.2011.633087

25. Belmokhtar AC, Hillion J, Segal-Bendirdjian E. Staurosporine induces apoptosis through both caspase-dependent and caspase-independent mechanisms. Oncogene 2001; 20: 3354-62. doi: 10.1038/sj.onc.1204436

26. Zhang XD, Gillespie SK, Hersey P. Staurosporine induces apoptosis of melanoma by both caspase dependent and independent apoptotic pathways. Mol Cancer Ther 2004; 3: 187-97. PMID: 14985459

27. D’Alimonte I, Ballerini P, Nargi E, Buccella S, Giuliani P, Di lorio P, et al. Staurosporine-induced apoptosis in astrocytes is prevented by A1 adenosine receptor activation. Neurosci Lett 2007; 418: 66-71. doi: 10.1016/j.neulet.2007.02.061

28. Leist $M$, Single $B$, Castoldi $A F$, Kühnle $S$, Nicotera $P$, Intracellular adenosine triphosphate (ATP) concentration: a switch in the decision between apoptosis and necrosis. J Exp Med 1997; 8: 1481-6. doi: $10.1084 /$ jem.185.8.1481

29. Jantas D, Krawczyk S, Lason W. The predominant protective effect of tianeptine over other antidepressants in models of neuronal apoptosis: the effect blocked by inhibitors of MAPK/ERK1/2 and PI3-K/Akt pathways. Neurotox Res 2014; 25: 208-25. doi: 10.1007/s12640-013-9430-3

30. ten Freyhaus H, Huntgeburth M, Wingler K, Schitker J, Bäumer AT, Vantle $\mathrm{M}$, et al. Novel Nox inhibitor VAS2870 attenuates PDGF dependent smooth muscle cell chemotaxis, but not proliferation. Cardiovasc Res 2006; 71: 33141. doi: 10.1016/j.cardiores.2006.01.022

31. Kim SY, Morgan MJ, Choksi S, Liu ZG. TNF induced activation of the Nox 1 NADPH oxidase and its role in the induction of necrotic cell death. Mol Cell 2007; 26: 675-87. doi: 10.1016/j.molcel.2007.04.021

32. Vanlangenakker $N$, Vanden Berghe $T$, Bogaert $P$, Laukenc $B$, Zobel $K$ Deshayes $\mathrm{K}$, et al. cIAP1 and TAK1 protect cells from TNF induced necrosis by preventing RIP1/RIP3 dependent reactive oxygen species production. Cell Death Differ 2011; 18: 656-65. doi: 10.1038/cdd.2010

33. Olguín-Albuerne M, Domínguez G, Morán J. Effect of staurosporine in the morphology and viability of cerebellar astrocytes: role of reactive oxygen species and NADPH oxidase. Oxid Med Cell Longev 2014; 2014: 678371. doi: $10.1155 / 2014 / 67837$

34. Laird MD, Wakade $\mathrm{C}$, Alleyne $\mathrm{CH}$, Dhandapani KM. Hemin induced necroptosis involves glutation depetion in mouse astrocytes. Free Radic Biol Med 2008; 45: 1103-14. doi: 10.1016/j.freeradbiomed.2008.07.003

35. Liu Q, Kang JH, Zheng RL. NADPH oxidase produces reactive oxygen species and maintain survival of rat astrocytes. Cell Biochem Funct 2005; 2: 93-100. doi: 10.1002/cbf.1171

36. Cabezas R, El-Bachá RS, González J, Barreto GE. Mitochondrial functions in astrocytes: neuroprotective implications from oxidative damage by rotenone. Neurosci Res 2012; 74: 80-90. doi: 10.1016/j.neures.2012.07.008

37. Kozieł R, Pircher $H$, Kratochwil M, Lener B, Hermann M, Dencher NA, et al. Mitochondrial respiratory chain complex I is inactivated by NADPH oxidase Nox 4. Biochem J 2013; 452: 231-9. doi: 10.1042/BJ20121778

38. Remijsen Q, Goossens V, Grootjans S, Van de Haute C, Vanlangenakker $\mathrm{N}$, Dondelinger $\mathrm{Y}$, et al. Depletion of RIPK3 or MLKL blocks TNF-driven necroptosis and switches towards a delayed RIPK1 kinase-dependent apoptosis. Cell Death Dis 2014; 5: e1004. doi:10.1038/cddis.2013.531 